\title{
LEISHMANIA (VIANNIA) SHAWI SP. N., A PARASITE OF MONKEYS, SLOTHS AND PROCYONIDS IN AMAZONIAN BRAZIL
}

\author{
R. LAINSON*, R. R. BRAGA**, A. A. A. DE SOUZA**, M. M. PÔVOA**, \\ E. A. Y. ISHIKAWA**, F. T. SILVEIRA**
}

SUMMARY. Leishmania (Viannia) shawi sp. n., is described from the monkeys Cebus apella and Chiropotes satanus, the sloths Choloepus didactylus and Bradypus tridactylus, the procyonid Nasua nasua, and the phlebotomine sandfly Lutzomyia whitmani, all from primary forest in the State of Pará, north Brazil. L. (V.) shawi is variably distinguished from all other known species within the subgenus Viannia by a combination of biological, biochemical and serological characters, as revealed by studies on morphology, isoenzyme profiles, kDNA buoyant densities and monoclonal antibodies.

Key-words : Leishmania (Viannia) shawi sp. n. Monkeys. Sloths. Procyonids. Lutzomyia whitmani. Amazonian Brazil.

\section{Leishmania (Viannia) shawi n. sp., parasite de Singes, de Paresseux et de Procyonidés en Amazonie brésilienne.}

RÉSUMÉ. Leishmania (Viannia) shawi sp. n., est décrit chez les singes Cebus apella et Chiropotes satanus, les paresseux Choloepus didactylus et Bradypus tridactylus, le coati Nasua nasua, et le phlébotome Lutzomyia whitmani, capturés dans la forêt primaire de l'État du Pará, Brésil. L. (V.) shawi a été distinguée de toutes les autres parasites dans le sous genre Viannia à travers un assemblage des caractères indiquées par les études morphologiques, profils enzymatiques, et anticorps monoclonaux.

Mots-clés : Leishmania (Viannia) shawi n. sp. Singes. Paresseux. Procyonidés. Lutzomyia whitmani. Amazonie.

\section{Introduction}

Leonidas Deane (1948) noted the presence of amastigotes in impression smears of spleen and liver from a two-toed sloth, Choloepus didactylus (L.) (Edentata: Bradypodidae), from Abaetetuba, Pará State, north Brazil, but he was uncertain if they were those of a Leishmania or developmental stages of Endotrypanum (a common intraerythrocytic trypanosomatid of sloths).

* The Wellcome Parasitology Unit, Caixa Postal 3, 66.000 Belém, Pará, Brazil. Pará, Brazil.

Accepté le 13 décembre 1988. 
What was thought to probably be the same parasite was later isolated from the viscera of C. didactylus, from Acará, Pará, by Lainson and Shaw (1972). This was undoubtedly a Leishmania species, which these authors later considered to "... differ from $L . b$. braziliensis and $L$. chagasi... ", and to be "... closest to $L$. b. guyanensis... " (Lainson and Shaw, 1979, 1987).

Lainson et al. (1988) recently recorded infections with a similar Leishmania in the skin of the monkeys Cebus apella (L.) and Chiropotes satanus (Hoffmansegg), from primary forest in the Serra dos Carajás, Pará, and (unpublished observations) from the skin of a coatimundi, Nasua nasua (L.) (Carnivora: Procyonidae) and the viscera of a three-toed sloth, Bradypus tridactylus (L.), in the same study area.

Although unaware of the common identity of these isolates at the time, the peripylarian development of the parasites from C. didactylus and Ce. apella in experimentally infected sandflies (Shaw, 1981; Lainson et al., 1988) showed that at least two isolates belonged to the subgenus Viannia Lainson and Shaw. Later, biological features, isoenzyme profiles and monoclonal antibodies have shown all the isolates from the above-mentioned animals to be indistinguishable and, furthermore, enabled their distinction from previously described species of Leishmania within the subgenus, including L. (V.) braziliensis Vianna, L. (V.) guyanensis Floch, L. (V.) panamensis Lainson and Shaw, L. (V.) lainsoni Silveira et al., and $L$. (V.) naiffi Lainson and Shaw.

It is the object of this communication to describe and name the organism Leishmania (Viannia) shawi sp. n., in honour of Dr. Jeffrey J. Shaw who has contributed so much to our knowledge of the leishmanias and leishmaniasis in the Americas.

\section{Materials and methods}

Morphological studies were based on both air-dried smears of amastigotes from the skin lesions of infected hamsters, fixed in absolute methyl alcohol, and similar smears fixed in Bouin's fluid. Preparations of promastigotes were from log-phase cultures of the parasite in Diffco blood-agar medium (Walton et al., 1977), and they were fixed by the same methods. Methyl alcohol fixed material was stained by the normal Giemsa method, and Bouin-fixed smears by a modified Giemsa method (Lainson, 1959). All measurements were made in $\mu \mathrm{m}$, using a Zeiss Morphomat 10.

Isoenzyme profiles were studied by starch-gel electrophoresis: for the preparation of lysates, other methods and enzyme abbreviations, see Miles et al. (1980). We used the enzymes MPI, 6PGDH, GPI, G6PD, PEP, ACON, MDH, PGM, ASAT, ALAT. Isolates studied included MCEB/BR/84/M8408 (type material), MCEB/BR/85/M9748 and MCEB/BR/85/M9805, from Ce. apella; MCHI/BR/ 84/M8955, MCHI/BR/84/M9194 and MCHI/BR/85/M10025, from Ch. satanus; MNAS/BR/85/M9554 from N. nasua; MBRA/BR/87/M11541 from B. tridactylus; $\mathrm{MCHO} / \mathrm{BR} / 71 / \mathrm{M} 1413$ from $C$. didactylus; IWHI/BR/83/M7731, IWHI/BR/ 
87/M11367, IWHI/BR/88/M12045, IWHI/BR/85/IM2308 (M10281) and IWHI/ BR/85/IM2326 (M10287), all from the sandfly Lutzomyia whitmani from the Serra dos Carajás (first three) and Tucurui (last two), Pará. Their enzyme profiles were compared with those of the standard marker strains for L. (V.) braziliensis (MHOM/BR/75/M2903) from the Serra dos Carajás, L. (V.) guyanensis (MHOM/ BR/75/M4147) from Monte Dourado, Pará and L. (Leishmania) amazonensis (IFLA/BR/67/PH8) from Belém, Pará.

All these stocks were examined with monoclonal antibodies specific to $L$. (V.) braziliensis (B18), L. (V.) guyanensis (B19), L. (V.) panamensis (B11) and six other braziliensis group specific monoclonals (B2, B5, B12 ; Col. 1-CXLII2C7-D3, Col. 2-CXLII-1D6-B8 and Col. 3-CXLII-3H1-B8) by methods previously described (Shaw et al., 1986).

\section{Results}

All the isolates from the mammalian hosts Cebus, Chiropotes, Nasua, Choloepus and Bradypus, and the sandfly Lutzomyia whitmani were indistinguishable on profiles for the 10 enzymes utilized, and separable from L. (V.) braziliensis, L. (V.) guyanensis and L. (L.) amazonensis by those of ASAT, ALAT, PGM, MPI and 6PGDH (fig. 4).

Specific monoclonal antibodies for $L$. (V.) braziliensis, L. (V.) guyanensis and L. (V.) panamensis distinguished these parasites from L. (V.) shawi. As is the case with both $L$. (V.) braziliensis and L. (V.) guyanensis, however (Shaw et al., 1986), there did seem to be some heterogeneity among the isolates, suggesting that serodemes of $L$. (V.) shawi exist.

Morphologically, the amastigotes and promastigotes of the new parasite call for little comment: both are small, as are those of other members of the braziliensis complex.

Leishmania (Viannia) shawi sp. n.

Specific Diagnosis

Type Host: the monkey Cebus apella (L.) (Cebidae): also recorded in the monkey Chiropotes satanus (Hoffmansegg) (Cebidae), the sloths Choloepus didactylus (L.) and Bradypus tridactylus (L.) (Edentata: Bradypodidae) and the coatimundi, Nasua nasua (L.) (Carnivora: Procyonidae).

Locality in Host: in edentates, the liver and spleen. In non-edentates, apparently limited to the skin.

Type Locality: site H7, in primary forest of the Serra dos Carajás, Pará, north Brazil $\left(6^{\circ} \mathrm{S}\right.$ : $\left.50^{\circ} .18^{\prime} \mathrm{W}\right)$.

Strain Designation: MCEB/BR/84/M8408. 
Amastigotes (fig. 1): length $3.01 \pm 0.25$ (2.45-3.58) for 50 measured; width $2.23 \pm 0.24(1.67-2.88)$ for 50 measured; kinetoplast length $0.96 \pm 0.17$ $(0.52-1.25)$ for 45 measured; kinetoplast width $0.57 \pm 0.10(0.40-0.90)$ for
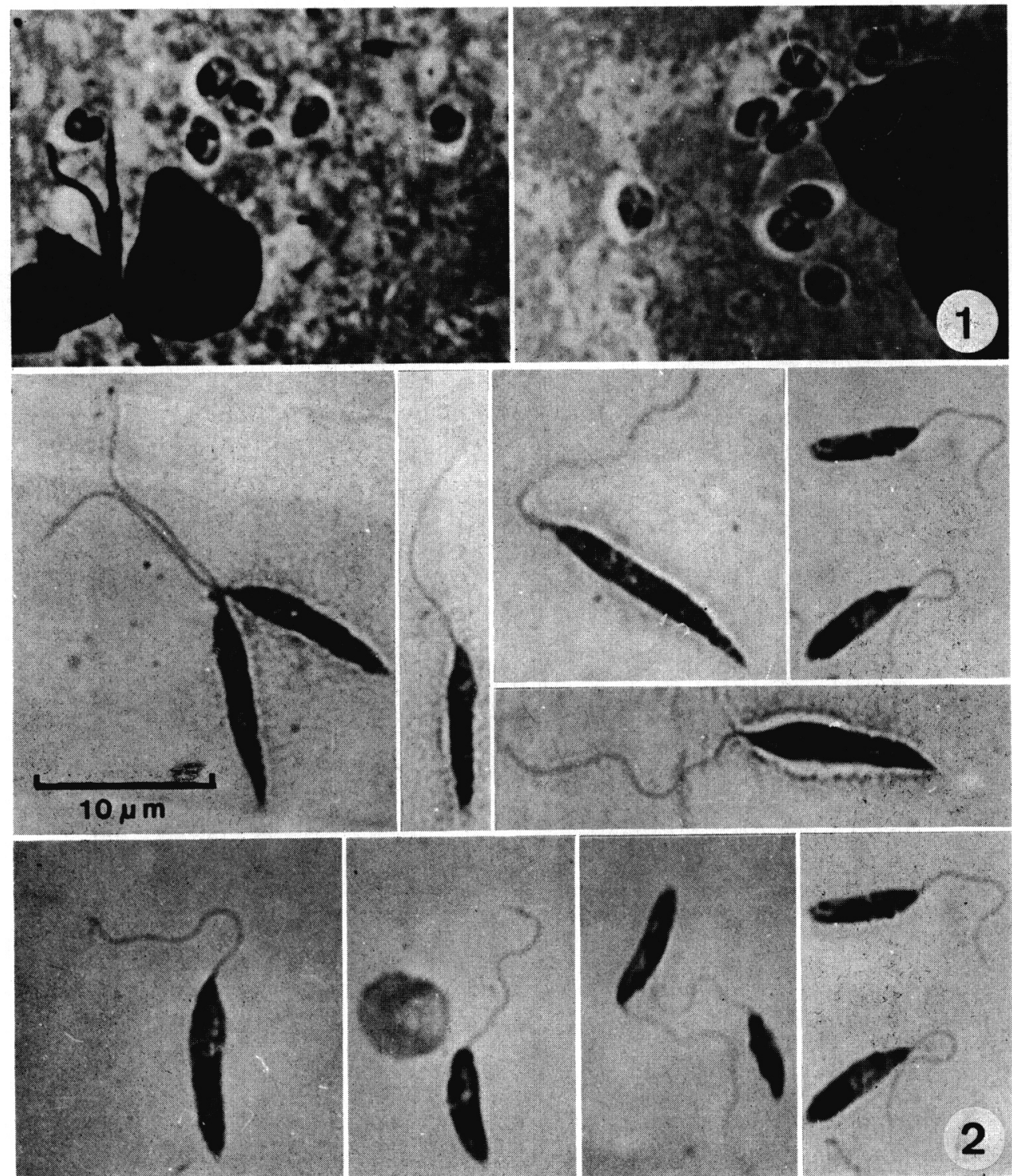

FIG. 1. - Amastigotes of Leishmania (Viannia) shawi sp. n., as seen in impression smears of hamster skin.

FIG. 2. - Promastigotes of $L$. (V.) shawi from a 7 day-old culture in Diffco NNN blood-agar medium. Both smears fixed in aqueous Bouin's fluid and stained by Giemsa's method. 
45 measured; nucleus length $1.33 \pm 0.12$ (1.06-1.50) for 42 measured; nucleus width $1.06 \pm 0.12(0.87-1.30)$ for 42 measured.

Promastigotes (fig. 2) : total body length $8.81 \pm 2.08$ (4.51-14.73) for 100 measured; width $1.56 \pm 0.33(0.64-2.63)$ for 100 measured; nucleus length $2.17 \pm 0.41$ (1.38-3.39) for 100 measured; nucleus width $1.18 \pm 0.18(0.63-1.66)$ for 100 measured; centre of nucleus to anterior tip $4.24 \pm 1.12$ (1.77-7.87) for 85 measured; centre of nucleus to mid-kinetoplast $2.88 \pm 1.62$ (1.32-5.11) for 100 measured; mid-kinetoplast to anterior tip $1.80 \pm 0.39(0.85-3.35)$ for 100 measured; free flagellum $14.45 \pm 2.48(7.80-19.15)$ for 97 measured; centre of nucleus to posterior tip $4.73 \pm 1.16(2.46-7.07)$ for 99 measured.

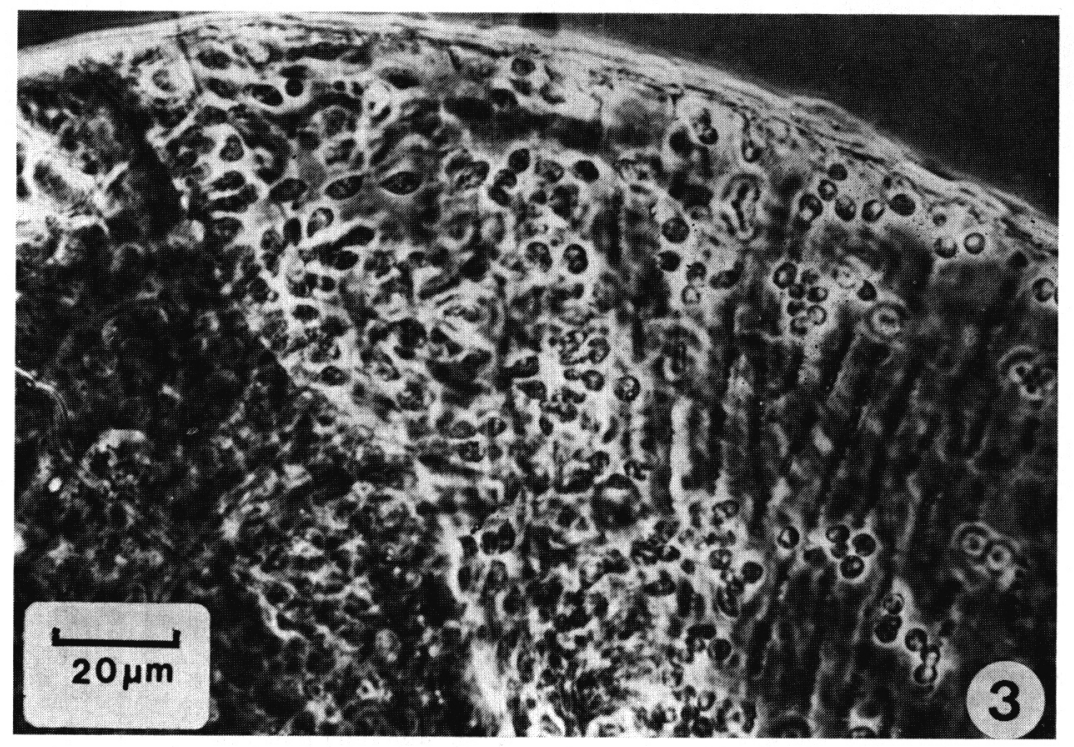

FIG. 3. - Experimental infection with L. (V.) shawi in the sandfly Lutzomyia longipalpis, 5 days after the infective blood-meal, showing large numbers of stumpy promastigotes and paramastigotes attached to the wall of the pylorus.

Development in the Sandfly Host: peripylarian, with the characters of the genus and subgenus.

Sandfly Vector: Lutzomyia (Nyssomyia) whitmani (Antunes and Coutinho).

Isoenzyme Profiles: distinguished from L. (V.) braziliensis, L. (V.) guyanensis and L. (L.) amazonensis by the profiles for ASAT, ALAT, PGM, MPI and 6PGDH.

Monoclonal Antibodies: separated from L. (V.) braziliensis, L. (V.) guyanensis, L. (V.) panamensis and L. (V.) naiffi by monoclonal antibodies specific for these parasites. 


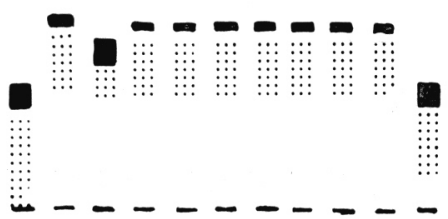

ASAT

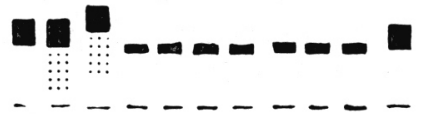

PGM

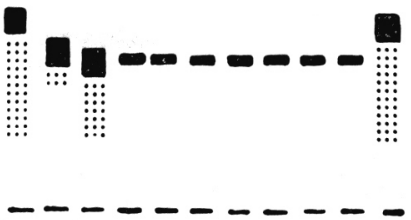

ALAT

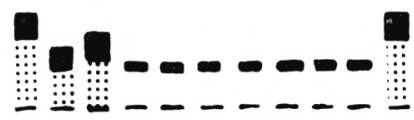

MPI

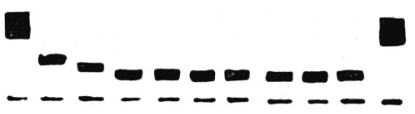

\section{PGDH}

FIg. 4. - Comparative enzyme profiles distinguishing L. (V.) shawi from 3 other Amazonian Leishmania species. Reading from left to right, the parasites are: (1) L. (Leishmania) amazonensis; (2) L. (V.) guyanensis; (3) L. (V.) braziliensis; (4-10) L. (V.) shawi from Cebus apella M8408, Chiropotes satanus M8955, Ch. satanus M9194, Ce. apella M9748, Ce. appela M9805, Ch. satanus M10025 and Nasua nasua M9554; (11) L. (L.) amazonensis. Scale: lines of application at the origin are approximately $1.0 \mathrm{~cm}$.

Kinetoplast DNA Buoyant Density: $1.692 \mathrm{ml}^{-\mathbf{1}}$. This differentiates the parasite from L. (V.) peruviana Velez, L. (V.) panamensis, L. (V.) naiffi and $L$. (V.) lainsoni Silveira et al.

Behaviour in Hamster: producing a small, self-limiting nodule or ulcer at the site of intradermal inoculation, with moderate numbers of amastigotes.

Behaviour in in vitro Culture: grows moderately well in Diffco blood-agar medium (B47: Walton et al., 1977).

Host Specificity: seemingly a fairly wide range of genera, and possibly predominantly in arboreal and semi-arboreal mammals due to the habits of the sandfly vector, Lutzomyia whitmani. So far, not recorded in man.

Type Material: hapantotype slides (amastigotes and promastigotes) held in the Department of Parasitology, the Instituto Evandro Chagas, Fundaçao SESP, Belém, Pará, Brazil. Cultures in cryobanks at the Instituto Evandro Chagas and the London School of Hygiene and Tropical Medicine. 


\section{Discussion}

The kDNA b. d. figure of $1.692 \mathrm{ml}^{-1}$ for $L$. (V.) shawi clearly indicates the parasite's inclusion in the braziliensis complex (kDNA b. d. 1.692-1.694, see Lainson and Shaw, Ann. Parasitol. Hum. Comp., 64, 1989, 3-9). On enzyme profiles and behaviour in both in vitro culture and hamster skin, the organism is closest to $L$. (V.) guyanensis.

Evidence incriminating $L u$. whitmani as the sandfly vector of $L$. (V.) shawi began with the record of 2 infections with a "Le. braziliensis subspecies " in specimens captured in Shannon traps, in our Serra dos Carajás study area, by Ryan et al. (1987), and this was followed up by the isolation of a similar parasite from 2 more $L u$. whitmani caught in CDC light-traps placed near sentinel Cebus monkeys in exactly the same locality (Lainson and de Souza, unpublished observations). In the light of these observations, isolates from the Carajás Lu. whitmani were included in subsequent characterization studies on $L$. (V.) shawi from the mammalian hosts, together with 2 other isolates from $\mathrm{Lu}$. whitmani made in a totally different area in Tucuruí, Pará. As shown in the present paper, the mammalian and sandfly isolates proved to be indistinguishable and we have little doubt that Lu. whitmani is an important vector of L. (V.) shawi. The arboreal nature of the mammalian hosts supports this view, as Lu. whitmani is a tree-trunk dwelling species, widely distributed in the Amazonian forests. In addition, the natural infections observed to date have all been massive ones, which extended into the anterior part of the cardia and oesophagus of the insect. Finally, 8 other similar infections recorded in $L u$. whitmani from Tucuruí are considered to have most probably been due to $L$. (V.) shawi, based on the behaviour of the isolates in hamster skin and in vitro culture (R. D. Naiff, personal communication).

Among the edentates examined (Choloepus and Bradypus), L. (V.) shawi was isolated only from the viscera, whereas the parasite appeared to be essentially a cutaneous one in the non-edentates (monkeys and the coatimundi). This striking difference in tissue-location is perhaps accounted for by the fact that all edentates have a low body temperature, which ranges from 32.7 to $35.5^{\circ} \mathrm{C}$ (mean $31.1^{\circ} \mathrm{C}$ ), compared with that of 36 to $38^{\circ} \mathrm{C}$ of most other mammals (McNab, 1985). While the division of leishmanial parasites into "visceral " and " cutaneous " species is not a sharp one (Lainson and Shaw, 1979), those most commonly associated with cutaneous leishmaniasis (in non-edentates) do tend to localize in such extremities as the ears, nose, feet and tail, where the body temperature is lower than that of other parts of the body.

Acknowledgments. - These studies were carried out under the auspices of the Wellcome Trust, London, and the Instituto Evandro Chagas of the Fundaçao SESP do Brasil. We are indebted to Dr. Douglas C. Barker for the kDNA b. d. figures for L. (V.) naiffi and L. (V.) lainsoni; to Dr. Diane McMahon-Pratt for provision of the monoclonal antibodies used in these studies; 
and to Roberto D. Naiff for providing the strains of $L$. (V.) shawi isolated from Lu. whitmani in Tucuruí. The following provided valuable technical assistance: José I. de Almeida, Iorlando da R. Barata, José P. Cruz, Augusto F. N. Filho, Francisco S. Gomes, Joao B. P. da Luz, Antônio F. P. Martins, Raimundo C. Mendonça, Antônio J. O. Monteiro, Deocleciano G. Primo, Maria das Gracas S. da Silva and Manoel C. M. de Souza.

\section{REFERENCES}

Deane L. M. : Abstract of discussion on C. A. Hoare's paper " The relationship of the haemoflagellates ". In: Proceedings of the 4th International Congress of Tropical Medicine and Malaria, Washington D. C., 10th-18th May, 1948, 2, 1117.

Lainson R. : Atoxoplasma Garnham, 1950, as a synonym for Lankesterella Labbé, 1899. Its life cycle in the English sparrow (Passer domesticus domesticus, Linn.). J. Protozool., 1959, 6, 360-371.

Lainson R., Shaw J. J. : Leishmaniasis of the New World: Taxonomic problems. Br. Med. Bull., $1972,28,44-48$.

LAInson R., SHAw J. J. : The role of animals in the epidemiolegy of South American Leishmaniasis. In: Biology of the Kinetoplastida, Volume 2 (W. H. R. Lumsden, D. A. Evans, eds.). Academic Press, London, New York, San Francisco, 1979, 1-116.

LAInson R., SHAw J. J. : Evolution, classification and geographical distribution. In: The Leishmaniases in Biology and Medicine, Volume I. Biology and Epidemiology (W. Peters, R. KillickKendrick, eds.), Academic Press Inc., London, 1987, 1-120.

Lainson R., Shaw J. J., Braga R. R., Ishikawa E. A. Y., de Souza A. A. A., Silveira F. T. : Isolation of Leishmania from monkeys in the Amazon Region of Brazil. Trans. R. Soc. Trop. Med. Hyg., 1988, 82, 231.

MaNAB B. K. : Energetics, population biolcgy, and distribution of Xenarthrans, living and extinct. In: The evolution and ecology of armadillos, sloths and vermilinguas (G. G. Montgomery, ed.). Smithsonian Institution Press, Washington, London, 1985, 219-232.

Miles M. A., Pôvoa M. M., de Souza A. A., Lainson R., Shaw J. J. : Some methods for the enzymic characterization of Latin-American Leishmania, with particular reference to Leishmania mexicana amazonensis and subspecies of Leishmania hertigi. Trans. R. Soc. Trop. Med. Hyg.,
1980, 74, 243-252.

Ryan L., LaInson R., Shaw J. J. : Leishmaniasis in Brazil: XXIV. Natural flagellate infections of sandflies (Diptera: Psychodidae) in Pará State, with particular reference to the role of Psychodopygus wellcomei as the vector of Leishmania braziliensis braziliensis in the Serra dos Carajás. Trans. R. Soc. Trop. Med. Hyg., 1987, 81, 353-359.

Shaw J. J. : The behaviour of Endotrypanum schaudinni (Kinetoplastida: Trypanosomatidae) in three species of laboratory-bred neotropical sandflies (Diptera: Psychodidae) and its influence on the classification of the genus Leishmania. In: Parasitological Topics: a presentation Volume to P. C. C. Garnham F. R. S. on the occasion of his 80th birthday, 1981. Soc. Protozool., Special Publication 1, Allen Press Inc., Laurence, Kansas, U. S. A., 1981, 232-241.

Shaw J. J., Lainson R., McMahon-Pratt D., David J. R. : Serodemes of the Leishmania braziliensis complex. In: Leishmania Taxonomie et Phylogenèse. Applications éco-épidémiologiques. Coll. int., CNRS/INSERM/OMS (2-6 July, 1984), IMEE, Montpellier, 1986, 143148.

Walton B. C., Shaw J. J., Lainson R. : Observations on the in vitro culture of Leishmanai braziliensis. J. Parasitol., 1977, 63, 1118-1119. 